\title{
Development of Industry-Friendly Rockbolts
}

\author{
G.R. Davison Gazmick Pty Ltd, Australia
}

\begin{abstract}
In an attempt to provide the best support system for rock excavations, the designers of ground support are constantly seeking ways to create rockbolts that meet a variety of demands. Load capacity, corrosion resistance and ease of installation are arguably the most important criteria used in any design. In seismic conditions, appropriate ductility is also a key performance parameter. Often, when designing or adapting rockbolts to specific environments, the ease of installation is not given the consideration that mine operators in particular require. The plethora of two pass rockbolt systems gives evidence to this fact.
\end{abstract}

This paper describes two rockbolts that have been designed to achieve industry requirements for strength, corrosion protection and ductility. Importantly, these bolts are not only designed to be installed in one pass, but are designed to be installed into standard $45 \mathrm{~mm}$ diameter drill holes. The requirement to match the installation needs of mine operators has resulted in rockbolts that are user friendly, whilst still providing all the engineering requisites of geotechnical practitioners.

The first bolt, B1, is $38 \mathrm{~mm}$ in diameter, with a nominal ultimate tensile strength of $20 \mathrm{t}$. The use of resin glue (a high density polyethylene sheath) and surrounding grout, provides at least three levels of corrosion protection to the core tendon. Fixation to the rock mass via the resin glue provides a stiff external support whilst the inner tendon can be manufactured as stiff or ductile, thus providing appropriate support for low or high stress rock environments.

The second bolt (Stiff Split Set®, patent pending) capitalises on the significant increases in frictional strength provided by the internal grouting of normal frictional stabilisers. In such cases, frictional strength can typically increase by a factor of four. The design of the bolt enables a simple one pass grouting method that occurs during bolt installation as opposed to a secondary expensive and time consuming process, that takes place after the bolt has been installed. The one pass grouting process speeds up the tunnelling or mining process considerably.

\section{Introduction}

The type of support that is available for use in underground excavations is extremely broad. With specific reference to rock re-enforcement, i.e. rockbolting, the range is extensive with a variety of rockbolts designed to perform a myriad of tasks. A broad list of these tasks is:

- Load capacity/strength.

- Immediate support.

- Corrosion resistance.

- Ductility, or lack thereof, depending upon the underground excavations stress environment.

- Ease of installation.

The designers of rockbolts attempt to provide solutions to the above criteria, however, in many instances, in an effort to meet the needs of the first three criteria, the fourth, ease of installation, is most problematic. The result is a plethora of ground support that requires two passes to install or do not suit typical drilling equipment. For example, post grouted bolts or bolts not suited to $45 \mathrm{~mm}$ diameter holes drilled by jumbos. However, other types of bolts suitable for insertion in $45 \mathrm{~mm}$ holes have been developed, such as the Jumbolt/Tiger bolt, hollow groutable bolt (HGB) and the CT bolt. These have enjoyed various degrees of commercial success with the CT bolt being somewhat of a benchmark for long-term support. Its main drawback is that it requires post grouting, i.e. a two pass process. 
Two pass processes greatly affect the development cycle times. The essence of high speed development is not necessarily a requirement to keep a jumbo drilling but rather the over-all requirement to keep the tunnel progressing and maintaining the best QA/QC on the installation of the ground support. In Australia, the most common solution to this problem of achieving the highest excavation progression, is to employ jumbos to install ground support, thus the requirement for bolts that are suited to jumbo holes.

The rockbolt needs to be matched to the $45 \mathrm{~mm}$ hole, matched to the jumbo slide and importantly, enable reliable simple installation.

Gazmick Pty Ltd has developed two novel designs that solve some of the problems discussed above.

\section{B1 (patented)}

The design of this rockbolt stemmed directly from the need to utilise a $45 \mathrm{~mm}$ diameter jumbo hole when bolting. Placing a $21 \mathrm{~mm}$ rockbolt in a $45 \mathrm{~mm}$ hole requires a significant extra amount of either grout or resin compared to $32 \mathrm{~mm}$ holes. Also the connection between rock, resin/grout and steel is less efficient when the higher annulus area of a $45 \mathrm{~mm}$ is used compared to a $32 \mathrm{~mm}$ hole.

The normal solution is to install solid bar rockbolts of approximately $21 \mathrm{~mm}$ diameter into $32 \mathrm{~mm}$ diameter holes. To do this, the drilling jumbo needs to change the drill string, i.e. a $32 \mathrm{~mm}$ bit, smaller drill rod and shank adaptor or smaller diameter shank. The logistics of managing the smaller drill string, development time loss, the cost of sourcing, stocking and maintaining two separate sized drill strings and accessories and relative inefficiency of this string coupled with high powered drills makes the use of standard $45 \mathrm{~mm}$ diameter highly preferable.

The B1 bolt comprises:

- A $38 \mathrm{~mm}$ diameter high density polyethylene (HDPE) threaded sheath.

- An inner tendon (typically at $21 \mathrm{~mm}$ diameter bolt).

The tendon is grouted into the sheath in the production factory using specific grouts and surface characteristics of the tendon. A schematic of a typical cross section of an installed bolt is illustrated in Figure 1, and test samples of $300 \mathrm{~mm}$ lengths are shown in Figure 2.

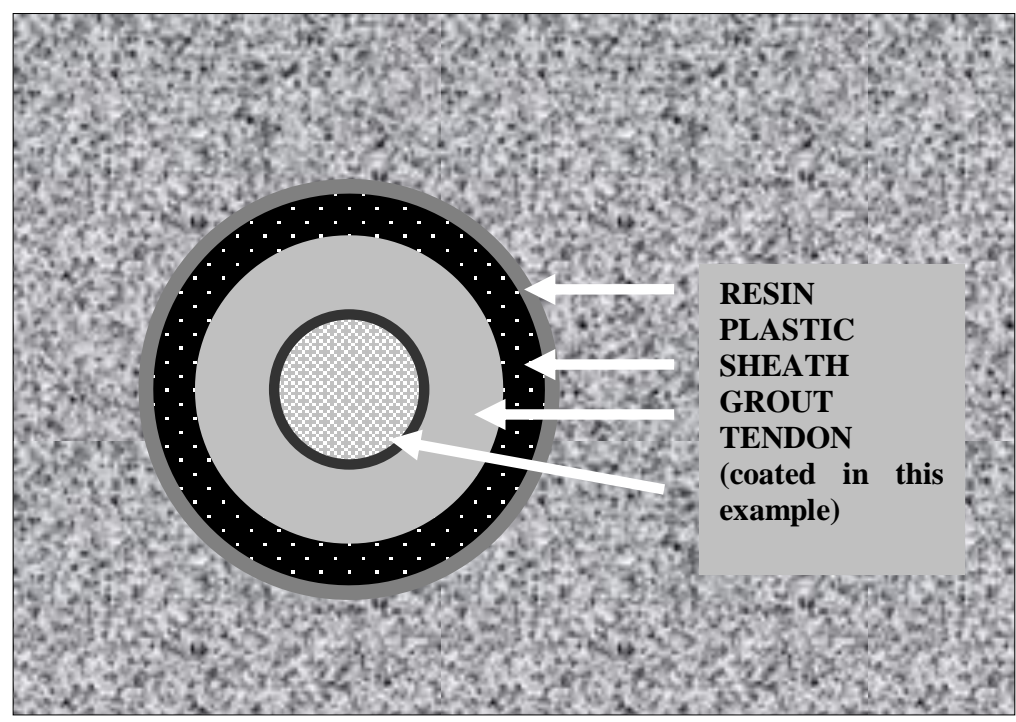

Figure 1 B1 cross section 


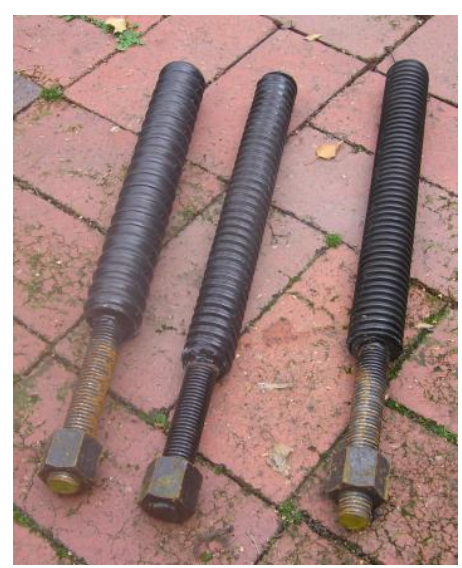

\section{Figure 2 B1 samples}

The assembly is installed into the $45 \mathrm{~mm}$ hole using a relatively low viscosity resin which is mixed via the threaded sheath as the bolt assembly is installed in the hole. See Figure 3 which shows a standard installation on a normal, non modified, jumbo slide.

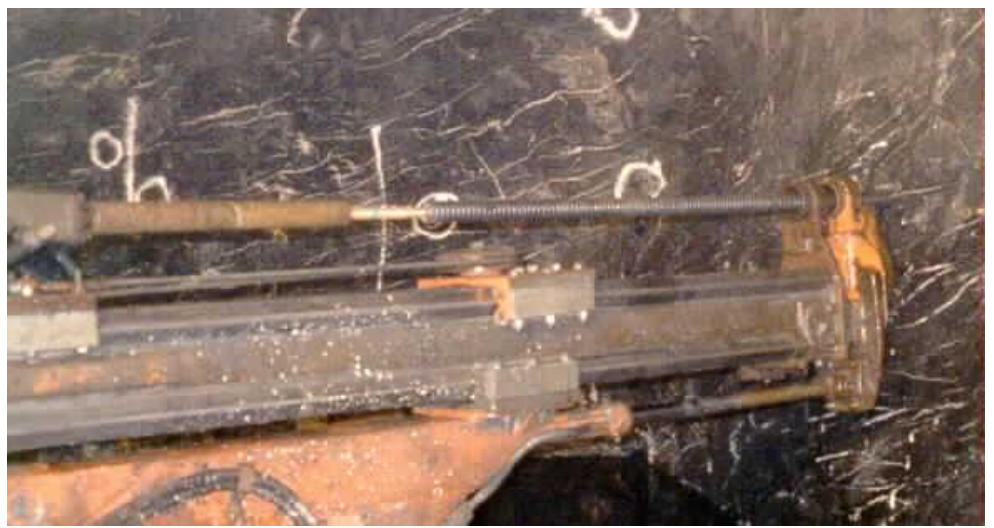

Figure 3 Installation of B1

The resin can be placed into the hole prior to the assembly installation via a variety of simple methods such as:

- Pneumatic installation.

- An attachment to the bolt assembly using a disposable connecting cartridge.

- Push installation using simple resin pushers.

B1 is not commercially available at the time of writing this paper but should be by the second half of 2008 . It is covered by patents and patent applications in Australia and other countries.

\subsection{Achievement of design criteria}

\subsubsection{Strength}

The outer sheath of the rockbolt is attached to the rock using extremely stiff resin. Pull tests performed on the samples, shown in Figure 2, have demonstrated a frictional strength of $180 \mathrm{kN}$ over the $300 \mathrm{~mm}$ length without the outer sheath or any other part of the assembly yielding. Tests were limited to a maximum $180 \mathrm{kN}$ so as not to damage the testing equipment.

The steel tendon can be a standard rockbolt having an ultimate tensile strength of 250 or $300 \mathrm{kN}$ depending on the requirement of the excavation's design engineers. 


\subsubsection{Intermediate support}

Intermediate support is achieved once the mixing/setting time of the resin expires; typically 30 to 60 seconds.

\subsubsection{Corrosion protection}

Corrosive fluids must penetrate three separate layers before being able to attack the inner tendon, i.e.:

- Encapsulating resin.

- The plastic sheath surrounding the tendon.

- The factory installed inner grout.

Extra corrosion protection via an extra plastic sheath and/or galvanised layers can be placed over the tendon thus providing additional protection for long-term bolting or highly corrosive applications. The threaded component that is exposed beyond the primary outer sheath can be manufactured from a different material, say stainless steel, and joined within the protective sheath thus offering an even higher degree of bolt longevity.

\subsubsection{Ductility or stiffness}

A stiff version of the bolt is achieved by the use of normal grout/bolt interface in the factory. Typically this stiffness is approximately $250 \mathrm{kN} / \mathrm{m}$ or greater. The overall stiffness of the bolt in this embodiment is extremely high with normal tendon rupture strengths of approximately $250 \mathrm{kN}$ over minimal (approximately $5 \mathrm{~mm}$ ) displacements.

Static ductility tests are being undertaken at present. Ductility is achieved by altering the grout/tendon interface. Examples of practical methods of doing this are:

- Using plain steel bar as the tendon.

- Coating the tendon with wax/plastic of other material to enable pre-determined slippage.

Once static tests have been done and proven that a ductile arrangement is practical, permission will be sought to undertake dynamic testing in appropriate test facilities. The overall initial aim is to produce a bolt that can provide a $200 \mathrm{~mm}$ displacement at $200 \mathrm{kN}$, i.e. approximately $40 \mathrm{~kJ}$ of energy absorption.

\subsubsection{Ease of installation}

Installation is comparable to typical resin bolt installation except that the ease of installation has been improved by increasing the diameter of the drill hole. As previously discussed, the primary advantage of utilising a $45 \mathrm{~mm}$ hole is the ability to do away with a $32 \mathrm{~mm}$ drill string although other benefits, as described above, ensue.

\section{Grouted "split set" stabilisers}

It is widely accepted that grouted split set or friction stabiliser rockbolts have significant frictional or pull out strength compared to non grouted embodiments.

Non grouted $45 \mathrm{~mm}$ diameter friction stabilisers exhibit a friction force of approximately 40 to $60 \mathrm{kN} / \mathrm{m}$ of embedment whilst fully grouted versions demonstrate approximately $150 \mathrm{kN} / \mathrm{m}$. Frictional strengths in excess of $150 \mathrm{kN} / \mathrm{m}$ have commonly been recorded (Fuller and Dugan, 1992; Villaescusa and Wright, 1997).

This occurs in any size split set, however, most examinations and testing have been done on the $45 \mathrm{~mm}$ bolts. Villeascusa and Wright (1997) when investigating permanent excavation support using cement grouted split set bolts, attributed the increase in friction mainly to:

"...the "partial dowelling and interlocking effect" achieved by the high strength grout being in contact (bonded) with the rock all the way along the split axis of the bolt." 
They added:

"The frictional resistance along the entire bolt axis is also increased by the high compressive strength grout minimizing any inward deformation in the bolt needed to achieve bolt slippage."

Thompson and Finn (1999) concurred with this view stating:

"The writers agree with both these proposed mechanisms of increased load transfer." and "...the first mechanism is most likely to be the cause of the increased load transfer." (referring to the grout making contact with the rock).

The following calculation demonstrates this to be an unlikely explanation.

An estimated adhesion of grout to rock $1 \mathrm{Mpa}\left(1,000,000 \mathrm{~N} / \mathrm{m}^{2}\right)$.

Approximate slot area, per metre length of an installed split set.

$1 \mathrm{~m} \mathrm{x} 17 \mathrm{~mm}=0.017 \mathrm{~m}^{2}$.

Resultant adhesion force $17 \mathrm{kN}$.

Observed increase in bolt friction per metre $150-40=90 \mathrm{kN}$.

The increase in friction is in excess of the $17 \mathrm{kN}$ developed through the grout/rock bond interface even when using a high grout adhesion figure of $1 \mathrm{MPa}$. It may be more representative to use a grout adhesion figure below $0.5 \mathrm{MPa}$ and therefore have a much lower adhesion force.

Thompson and Finn (1999) also show that jumbo holes, whilst nominally $45 \mathrm{~mm}$, can actually vary in diameter by approximately $1 \mathrm{~mm}$ along their length. When a normal split set bolt is installed into such a hole the bolt conforms to the shape and diameter of the bore hole. If rock failure occurs the ungrouted bolt will again deform as it is being dragged out of the hole.

In the grouted embodiment, the bolt is installed as a ductile member but after the grout sets, the shape is set thus restricting movement, i.e. increasing load capacity. The author believes that this is the primary mechanism by which the friction increases. Subsequent personal communication with Thompson has established a concurrence with this view.

It is extremely common in Australia to observe split set failures where the failed rock has many split sets left in the failed wedge or slab. They do not break in tension because friction force is so low that it cannot combine with typical embedment lengths to fail the steel that has a nominal tensile strength of $180 \mathrm{kN}$. This is the underlying reason that split set manufacturers have not increased split set steel strength. By far the most important limiting factor in a split set installation is the friction between the bolt and the rock.

By grouting a split set it could be possible to utilise higher steel strengths if required. In the grouted embodiment it is possible to fully utilise the steel strength and, with a friction force of $150 \mathrm{kN} / \mathrm{m}$, an embodiment length slightly in excess of one metre will fail the steel. Grouting split sets significantly change their performance characteristics and, this must be considered and understood, during the selection process of ground support when conducting an excavation design.

\section{Stiff Split Set}

The Stiff Split Set is a split set that has the grout placed internally before the bolt is inserted into the rock mass, in one pass and embodies the advantages mentioned previously. With additional research on the dynamic capabilities of the bolt, the design may be able to capture most of the criteria mentioned at the beginning of this paper. The primary advantage of this bolt over a normal grouted split set is that the grouting process is simple and it takes place in one pass during bolt installation. Figure 4 shows a cross section of the Stiff Split Set bolt.

The bolt has been commercially available in a developmental stage since early 2007. It is now widely available and at the time of writing this paper, in excess of 60,000 units have been sold. The Stiff Split Set is covered by patent applications in Australia and other countries. 


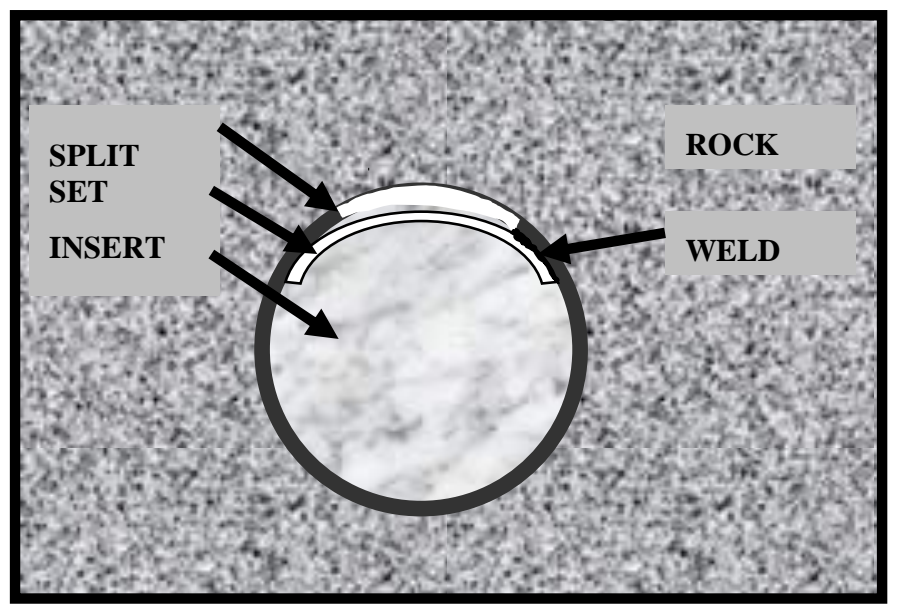

Figure 4 Cross section of the Stiff Split Set

\subsection{Achievement of design criteria}

\subsubsection{Strength}

The Stiff Split Set is similar to a normal split set except that the slot in the split is covered with an affixed insert. The covering is internal and fixed on one side by welding or gluing of the split set allowing the cover to "float" on the other side. See Figures 5 and 6.

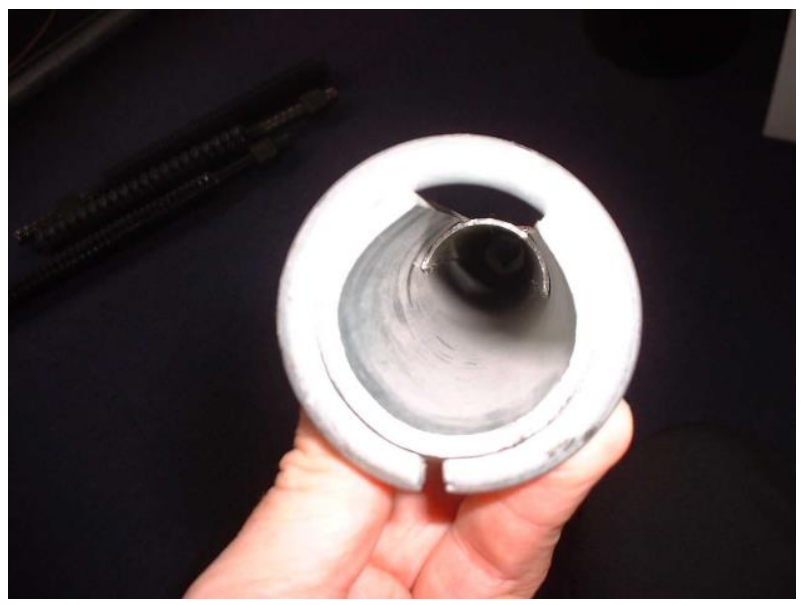

Figure 5 End view of Stiff Split Set showing floating insert

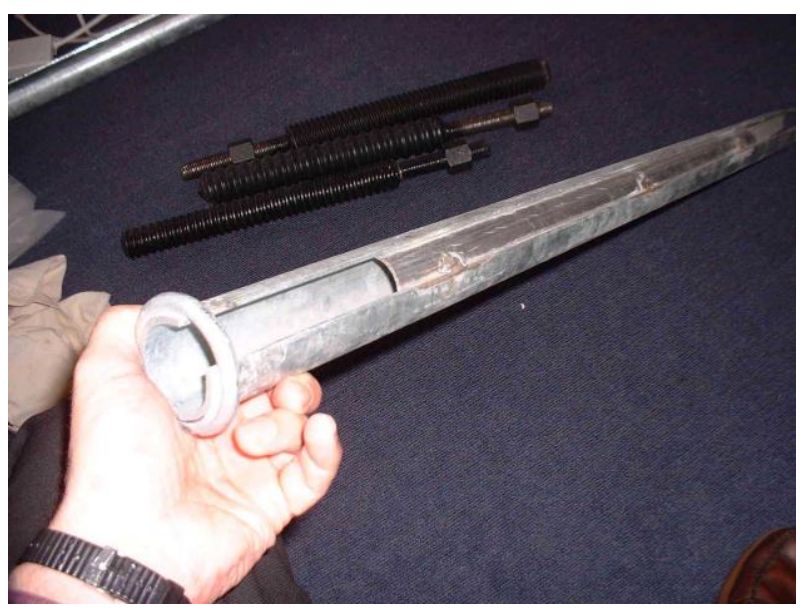

Figure 6 Side view of Stiff Split Set prototype 
Permeable cement cartridges matching the internal diameter of the non-installed bolt are inserted in a water bath until full hydration occurs (approx. 45 seconds), Figure 7.

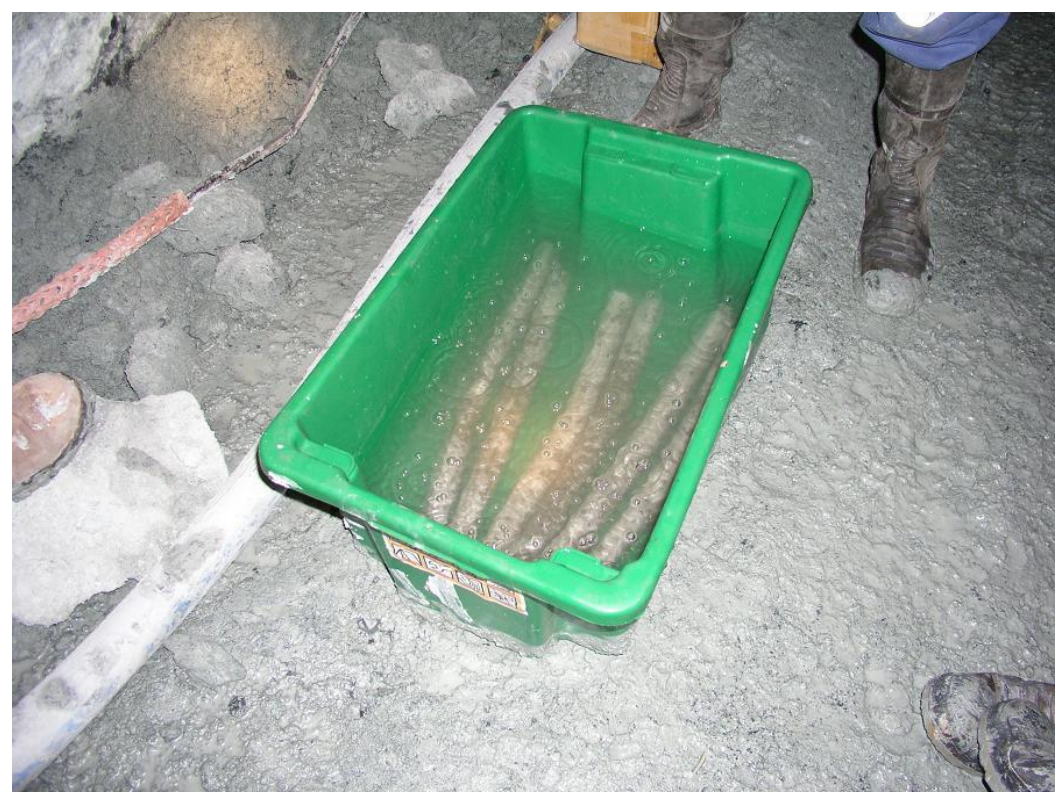

\section{Figure 7 Hydration of cement cartridges}

These cartridges are placed inside the bolt. The bolt is placed on the jumbo slide and inserted into the drill hole.

Numerous static pull tests on site have been conducted. In normal installations a frictional force of $150 \mathrm{kN} / \mathrm{m}$ of embedment is demonstrated (the actual frictional resistance developed will depend upon the type of ground in which the bolt is installed and the hole diameter).

The first full length test of a $2.4 \mathrm{~m}$ long bolt resulted in the bolt breaking approximately $75 \mathrm{~mm}$ from the pull ring at $200 \mathrm{kN}$ (see Figures 8 and 9).

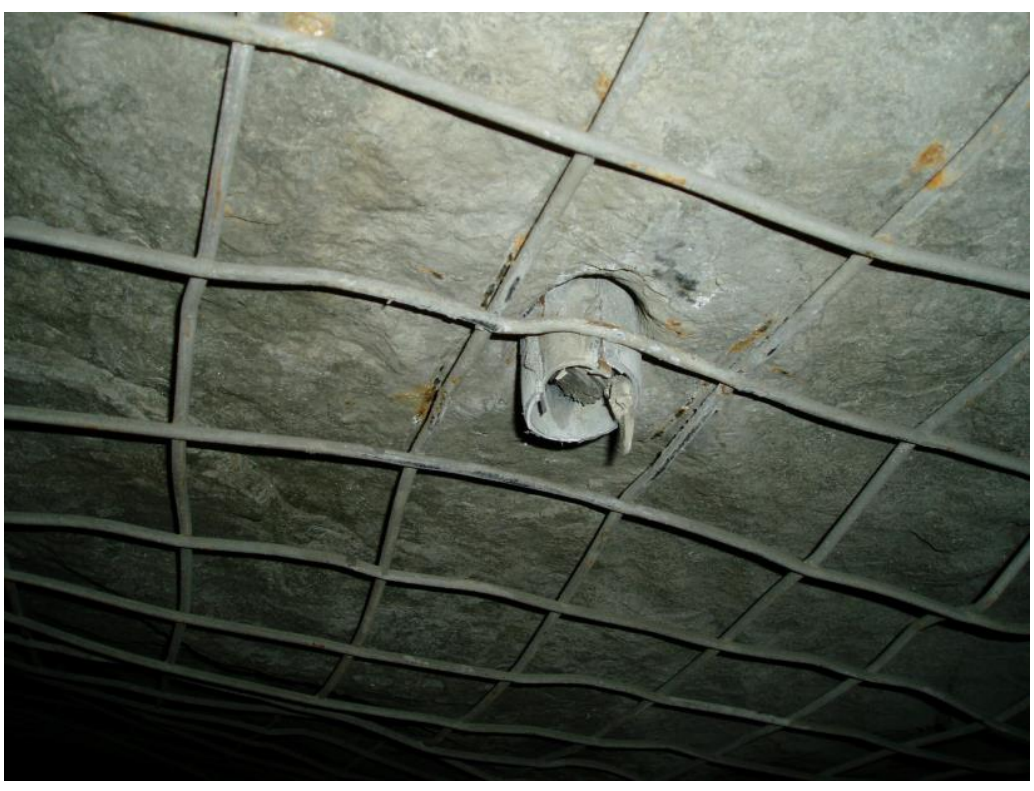

Figure 8 Remnant of a Stiff Split Set in a back hole after pull testing to $200 \mathrm{kN}$ 


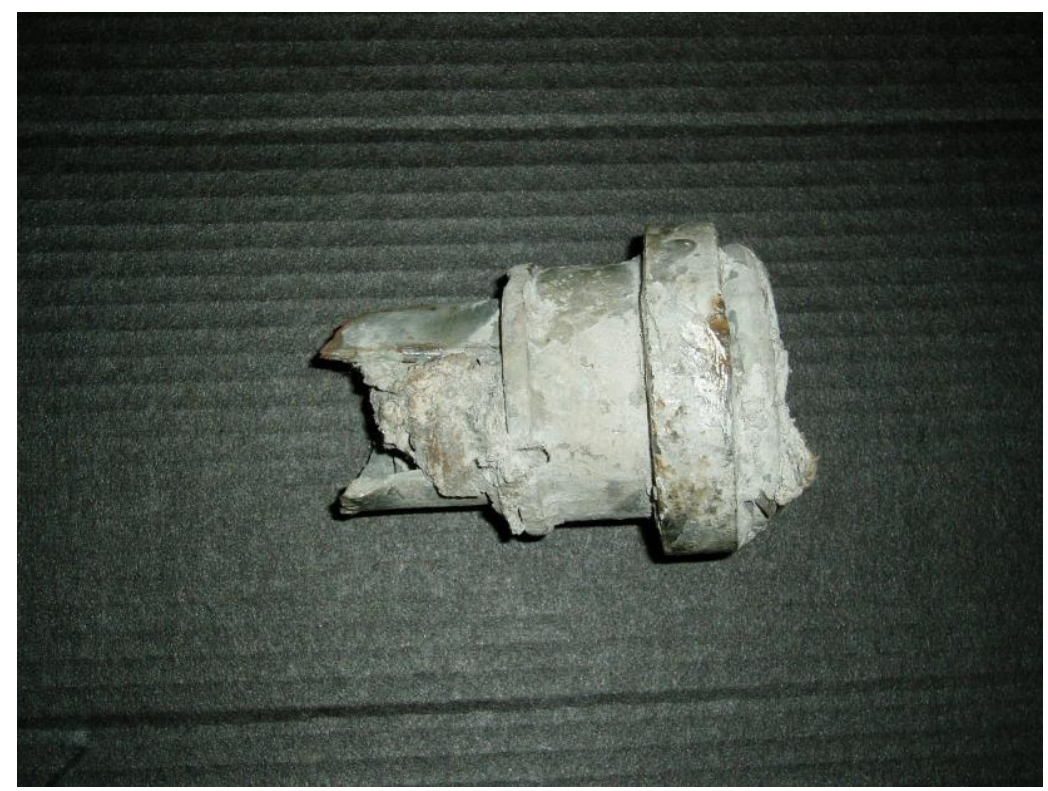

Figure 9 Broken section of a Stiff Split Set after pull testing to $200 \mathrm{kN}$

In a typical Rocscience Unwedge analysis, the resultant factor of safety for a normal split set installation increases from 0.9 to 2.1 simply by grouting the bolt thereby achieving a friction increase from 40 to $150 \mathrm{kN} / \mathrm{m}$ of embedment. The increase in performance has allowed many mine operators the opportunity to consider a three metre version of the Stiff Split Set for development intersections where wide spans occur. During the design process, the potential for corrosion must also be considered, however, as illustrated in the Unwedge analysis, in the right environment these bolts can perform a similar function as cable bolts.

\subsubsection{Immediate support}

The bolt provides immediate support and significant increases in friction within eight hours. This matches with other published data (Villaescusa and Wright, 1997). As the grout continues to set over time, the friction continues to increase.

\subsubsection{Corrosion}

Corrosion of split sets is reduced by the filling of the internal part of the bolt by grouting. Whilst corrosion cannot be eliminated totally for steel and galvanised bolts, the grouting of bolts reduces exposure and thus, corrosion potential. The possible use of differing grades of stainless steel in bolt manufacture and the large frictional resistance of Stiff Split Sets also offers practitioners significant opportunities in support design.

\subsubsection{Ductility}

Normal $45 \mathrm{~mm}$ split sets are extremely ductile, pulling out of the rock at approximately $100 \mathrm{kN}$ with a resultant energy absorption of approximately $20 \mathrm{~kJ}$ over a displacement of $200 \mathrm{~mm}$.

Data published by Kaiser et al. (1996) indicate a split set energy absorption in the range of 5 to $15 \mathrm{~kJ}$. It must be noted that this data, whilst labelled "split set bolt", the test bolts were $33 \mathrm{~mm}$ split sets with a peak load range of 50 to $100 \mathrm{kN}$, a displacement of 80 to $200 \mathrm{~mm}$ and curiously energy absorption of 5 to $15 \mathrm{~kJ}$. Kaiser (pers. comm., 2007) confirmed that deformation/displacement is matched to other types of bolts and the split set bolt's deformation is limited to the deformation of other types of bolts, i.e. a nominal $150 \mathrm{~mm}$, thus the relatively low energy absorption figure.

A fully grouted Stiff Split Set is a stiff embodiment generally suited to low stress environments. Trials are currently being undertaken to increase the energy absorption of the bolt. The aim of these trials is to achieve a bolt that will deform at $180 \mathrm{kN}$ over a displacement of $200 \mathrm{~mm}$ thus providing a maximum of $36 \mathrm{~kJ}$ of energy absorption. 


\subsubsection{Ease of installation}

The normal process of grouting of split sets is cumbersome and usually involves at least two operators, grouting equipment and a service vehicle. Grout must be mixed, pumped and the equipment cleaned. Importantly, the grouting process inevitably holds up the development process and therefore improvements are highly sought after.

The installation of one pass grouted Stiff Split Set only increases the bolting time marginally ( 45 seconds per bolt) for a single bolting operator. If the bolting operation uses the services of a second person, a nipper, there is no reduction of bolting productivity.

Feedback from jumbo operators during prototype testing has been extremely positive with many expressing a desire to install the Stiff Split Set in preference to resin or other grouted bolts because of the ease of bolt installation.

Single pass bolting/grouting speeds up the development process because it eliminates the need to return for a second stage of grouting.

\section{Conclusions}

Improvements to ground support are being constantly sought however, in many instances the designers of bolts are unable to provide a complete package, i.e. a bolt that works geotechnically and which is easy to install. The bolts described in this paper, B1 and the Stiff Split Set were designed with ease of installation as a primary goal. Other design aspects such as strength, immediate support, corrosion resistance, and ductility, (or lack thereof where appropriate), have been given careful consideration and in most instances have been achieved. Work will continue to be undertaken by Gazmick Pty Ltd to improve the bolts in areas where end users believe that a design deficit exists.

\section{Acknowledgements}

The author would like to thank split set Mining Systems (a division of Phoenix Metalform) for their assistance in bringing the Stiff Split Set into commercial production and for supplying some of the figures and data used in this paper and the shareholders of Gazmick Pty Ltd, who have funded the development of the bolts over a considerable period of time.

\section{References}

Fuller, P.G. and Dugan, K.J. (1992) Factors affecting ground support performance in mining. 5th Underground Operator's Conference, Ballarat 14-16 July, Australasian Institute of Mining and Metallurgy, pp. 139-144.

Kaiser, P.K., McCreath, D.R. and Tannant, D.D. (1996) Canadian Rockburst Handbook, Geomechanics Research Centre, Laurentian University, 2, pp. 2-22.

Thompson, A.G. and Finn, D.J. (1999) The performance of grouted split tube rockbolt systems. Rock Support and Reinforcement Practice in Mining, Villaescusa, Windsor and Thompson (editors), Balkema, Rotterdam, pp. 91102.

Villaescusa, E. and Wright, J. (1997) Permanent excavation support using cement grouted split set bolts. Proceedings International Symposium on Rock Support, Lillehammer, Norwegian Society of Chartered Engineers, Norway, pp. 660-670. 
